\title{
Sensitivity Assessment using Genetic Algorithm for Optimal Design of RC Ring Wall Foundation of Liquid Storage Tanks
}

\author{
Gautam Acharyya, Sridhar Reddy E, Pralhad Pawar
}

\begin{abstract}
Hydrocarbons and chemical industries extensively use storage tanks made of steel for storing large quantities of liquids. These tanks are typically supported on a RC ring wall foundation. This paper presents a method to minimize the cost of RC Ring Wall Foundations and study the sensitivity of this cost towards the different design parameters. The optimization process is developed through the use of genetic algorithm which simulates the biological evolution for the fittest (optimized) organism Previous studies on use of genetic algorithm in structural engineering has been applied to different structures like frames beams, columns etc. This paper extends the use of genetic algorithm to ring wall foundations of liquid storage tanks. The objective function for optimization includes the costs of concrete, steel, formwork and excavation whose sensitivity is analysed for parameters like grade of steel, concrete, seismic and wind loading for different tank sizes. All the constraints functions are set to meet the design requirements as per Indian Standard Codes and construction industry practices. Eight cases of parametric study are considered in order to illustrate the applicability of the genetic algorithm design model. It is concluded that this approach is economically more effective compared to conventional methods for design and sensitivities of different design parameters can be quickly assessed. Additionally this design methodology can be extended to deal with other types of structures as well.
\end{abstract}

Keywords: cost minimization, reinforced concrete ring wall, Indian Standard Codes, genetic algorithm, sensitivity study, parametric study.

\section{INTRODUCTION}

In Oil, Gas and Hydro carbons Industries, large number of tanks are required for storing various liquids. These storage tanks are generally made of Mild Steel, which are mounted on Reinforced Concrete foundations as per the requirement. These foundations are to be designed for Tank Weight, Stored liquid weight, Wind and Seismic Forces etc. For anchoring the tank, anchor bolts may be required. Different process conditions like empty condition, operating condition, hydro test condition are to be considered while designing tank foundations.

Revised Manuscript Received on February 05, 2020.

* Correspondence Author

Gautam Acharyya*, Deputy Manager-Engineering, Tata Project Limited,One Mumbai-400076, India. $\quad$ E-mail: gautamacharyya@tataprojects.com

Sridhar Reddy E, General manager- Engineering, Tata Project Limited, Mumbai-400076, India. Email: sridharellanki@tataprojects.com

Pralhad Pawar, Chief Technology and Engineering officer, Tata Project Limited, Mumbai-400076, India.

(c) The Authors. Published by Blue Eyes Intelligence Engineering and Sciences Publication (BEIESP). This is an open access article under the CC BY-NC-ND license (http://creativecommons.org/licenses/by-nc-nd/4.0/)
Ringwall foundation is a peripheral wall and footing structural system along the circumference of a tank shell which support the tank and its content.

The Ring wall foundation for these tanks are different from ordinary building foundation design. Although the foundation receives the complete tank shell load, however only about 10 percent of the load of the liquid weight and base plate is transferred to

the Ring Wall, the rest is directly transferred to the compacted soil infill. Therefore, under lying soil strata and bearing capacity plays a major role. Also the settlement analysis has to be carried out separately as the outer pipes connected to tank may get disturbed due to differential settlement between Ring Wall Foundation and Internal fill. The objective of the study is to analyse the effects of different parameters like height, diameter of tank, wind speed, earthquake zone, grade of steel and grade of concrete on sizing of ring wall foundation and subsequently quantities of concrete and reinforcement. The objective function is usually simplified to represent the cost equivalent of volume of concrete and area of steel required, disregarding the costs of shaping and the construction details. The effect of formwork and excavation on the above mentioned objective function is also considered as separate study cases.

This study presents an objective function that considers the total cost ratio i.e. total cost of Ringwall divided by cost of concrete and not the absolute cost of ring wall. The cost ratio and not the absolute cost have been considered because the unit rate of concrete and steel may vary based on a lot of factors; the ratio unlike the total cost is relatively independent to such variations. Sensitivity analysis of this cost ratio is dealt in the study as well using Genetic Algorithm methodology.

Genetic algorithms (GA) are search algorithms based on the principles of natural selection and genetics, introduced by $\mathrm{J}$ Holland [12] and simulates the biological evolution of living beings [13]. Genetic algorithms abstract the problem space as a population of individuals, and try to explore the fittest individual by producing generations iteratively. The Genetic Algorithm (GA) algorithm is used to solve the nonlinear problem to derive the optimized value of objective function. It is a very reliable and robust algorithm. Many similar studies have been carried out in the field of structural engineering using Genetic Algorithm.

Malleshappa etal [1] formulated the optimization of RC column and isolated footing using Genetic algorithm. Sashidhar etal [2] used Genetic Algorithm technique for optimizing design of Reinforced concrete retaining walls. Rajeev etal [3] studied the application of Genetic Algorithm in structural optimization of Concrete frames. 
Renitha etal [4] studied the optimized cost design of RC frames according to Indian standard codes using Genetic Algorithm. Ferhat [5] studied the cost and weight optimization of ordinary concrete and HSC beam using generalized reduced gradient (GRG) algorithm according to Eurocode2. Aga etal [6] investigated the cost optimization of reinforced concrete (RC) frames based on specification in ACI code.

The frames were analysed for gravity loads as well as seismic loads. Sivanandam and Deepa [7] explained the step by step programming procedure for Genetic Algorithm.

As an extension to the previous studies mentioned above on cost minimization of RC Structures, the current work shows a method for minimizing the cost of reinforced concrete ring wall foundation according to Indian Standard Code IS456 [8]. This minimum design value is further considered for sensitivity analysis of cost ratio versus the design parameters like different grades of steel, grades of concrete, wind speeds, earthquake zones, height and diameter of tank.

\section{DESIGN PHILOSOPHY OF RC RING WALL AND FOOTING}

The geometry, structural details and loads coming on the Ring Wall are illustrated in Fig 1 and 2.

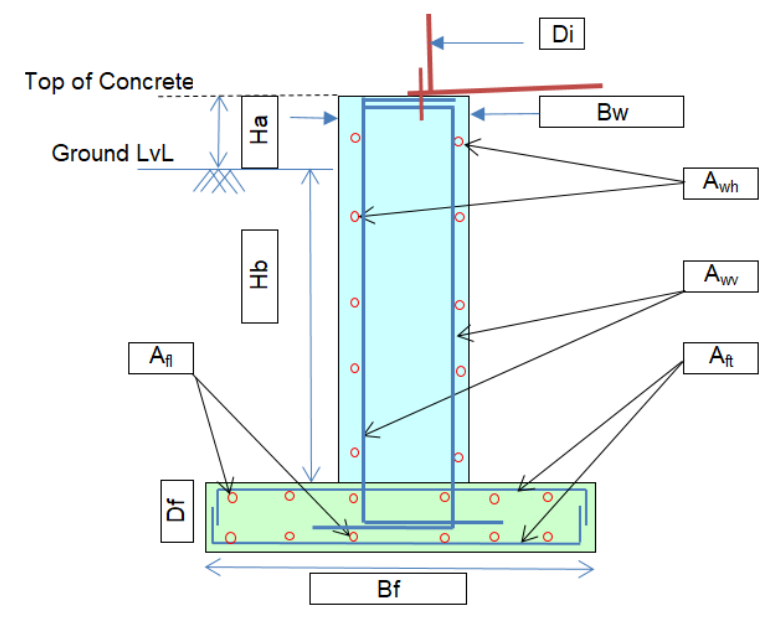

Fig. 1. Typical Ring Wall Cross Section

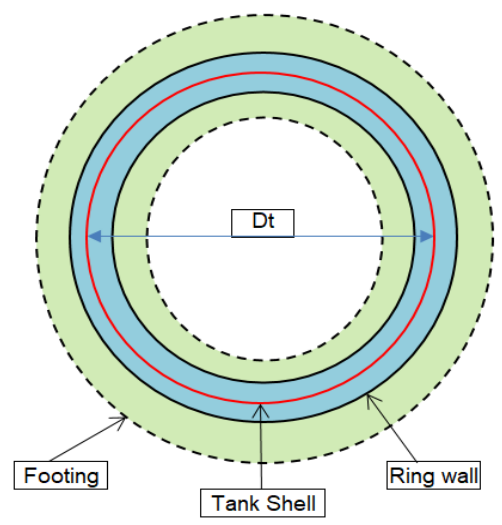

Fig. 2.Top Plan of Ring Wall

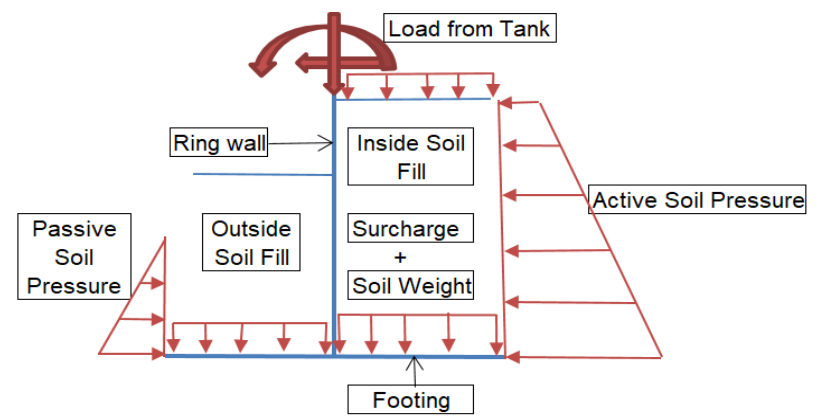

Fig. 3.Loading on Wall and Footing

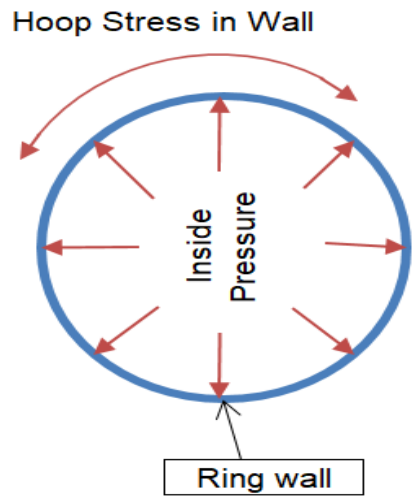

Fig. 4.Hoop stress in ring wall

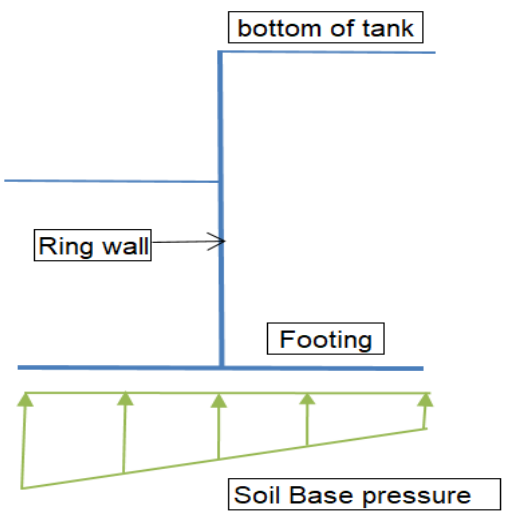

Fig. 5.Soil Base Pressure

In Figure 1 and 2, it can be seen that as typical RC Ring Wall Foundation consists of 2 parts i.e. the ring wall and the footing base. A small fraction of the wall is kept above ground as clearance. The tank base partially rests on the wall and the remaining part rests on the compacted soil infill. Anchor bolts hold the tank in position against uplift. Reinforcement steel details is also shown in Figure 1.

In the loading pattern shown in Figure 3, it can be observed that lateral active pressure from the inside soil fill shall apply on the ring wall. In addition to this, loading from the tanks will also be transferred to the ring wall directly and as surcharge on the soil fill. The lateral soil pressure and surcharge will be transferred as hoop stress onto the ring wall as shown in Figure 4 for which it shall be designed.

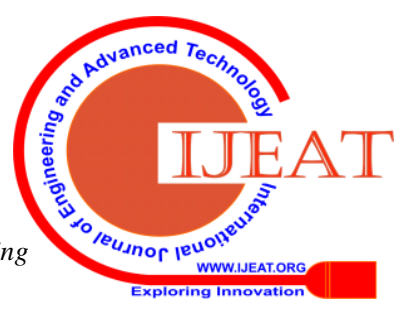


The base footing shall be designed for moment and shear resulting from the soil base pressure as shown in Figure 5.

\section{FORMULATION OF THE OPTIMIZATION PROBLEM}

\section{A. Design variables}

The design variables selected for the optimization are presented in Table I. They shall vary in all the simulations

Table- I: Definition of design variables

\begin{tabular}{|l|l|}
\hline $\begin{array}{l}\text { Design } \\
\text { variables }\end{array}$ & Definition \\
\hline $\mathrm{Di}$ & Internal Diameter of Tank \\
\hline $\mathrm{B}_{\mathrm{w}}$ & Width of Ring Wall \\
\hline $\mathrm{B}_{\mathrm{f}}$ & Width of Footing \\
\hline $\mathrm{D}_{\mathrm{f}}$ & Thickness of Footing \\
\hline $\mathrm{A}_{\mathrm{wh}}$ & $\begin{array}{l}\text { Area of hoop reinforcement in } \\
\text { c/s of wall }\end{array}$ \\
\hline $\mathrm{A}_{\mathrm{wv}}$ & $\begin{array}{l}\text { Area of vertical reinforcement } \\
\text { in c/s of wall }\end{array}$ \\
\hline $\mathrm{A}_{\mathrm{ft}}$ & $\begin{array}{l}\text { Area of tensile reinforcement in } \\
\text { c/s of footing }\end{array}$ \\
\hline $\mathrm{A}_{\mathrm{fl}}$ & $\begin{array}{l}\text { Area of distributed } \\
\text { reinforcement in c/s of Footing }\end{array}$ \\
\hline
\end{tabular}

The constants adopted for design are shown in Table II. They shall not vary in any of the simulations

Table- II: Definition of constants

\begin{tabular}{|l|l|}
\hline \multicolumn{1}{|c|}{$\begin{array}{c}\text { Design } \\
\text { variables }\end{array}$} & \\
\hline $\mathrm{H}_{\mathrm{b}}$ & Depth of foundation below ground level \\
\hline $\mathrm{H}_{\mathrm{a}}$ & Width of Ring Wall \\
\hline$\rho_{\mathrm{s}}$ & Width of Footing \\
\hline $\mathrm{SBC}$ & Thickness of Footing \\
\hline $\mathrm{C}_{\mathrm{S}}$ & Cost of Steel per kg \\
\hline
\end{tabular}

Besides Table I and II, there are certain variables which shall vary only in a particular study case, for other cases they remain constant. They are shown in table III

Table- III: Definition of case based variables

\begin{tabular}{|l|l|}
\hline \multicolumn{1}{|c|}{$\begin{array}{c}\text { Design } \\
\text { variables }\end{array}$} & \\
\hline $\mathrm{C}_{\mathrm{C}}$ & Material Cost of Concrete per $\mathrm{m}^{3}$ \\
\hline $\mathrm{C}_{\mathrm{f}}$ & Cost of formwork per $\mathrm{m}^{2}$ \\
\hline $\mathrm{C}_{\mathrm{E}}$ & Cost of excavation per $\mathrm{m}^{3}$ \\
\hline $\mathrm{f}_{\mathrm{ck}}$ & Grade of concrete \\
\hline $\mathrm{f}_{\mathrm{y}}$ & Grade of steel \\
\hline $\mathrm{H}_{\mathrm{t}}$ & Height of Tank \\
\hline
\end{tabular}

\section{B. Objective Function}

The objective function to be minimized in the optimization problems is the total cost of construction material i.e. concrete and steel. This function can be defined as:

$$
\begin{aligned}
C_{T}= & C_{c}\left[\pi \operatorname{Di}\left\{B_{w}\left(H_{b}+H_{a}\right)+D_{f} B_{f}\right\}\right] \\
& +C_{s}\left[\pi \operatorname{Di}\left(A_{w h}+A_{w v}+A_{f t}+A_{f l}\right) \rho_{s}\right]
\end{aligned}
$$

Where $\mathrm{C}_{\mathrm{T}}$ is the total cost of the RC Ring Wall foundation Thus the Total Cost Ratio (TCR) function to be minimized can be converted to

$$
\begin{aligned}
\frac{C_{T}}{C_{c}} & =\pi \operatorname{Di}\left[B_{w}\left(H_{b}+H_{a}\right)+D_{f} B_{f}\right] \\
& +\frac{C_{s}}{C_{c}}\left[\pi \operatorname{Di}\left(A_{w h}+A_{w v}+A_{f t}+A_{f l}\right) \rho_{s}\right]
\end{aligned}
$$

If cost of formwork is taken into account, the TCR function can be formulated as

$$
\begin{aligned}
\frac{C_{T}}{C_{c}}= & \pi \text { Di }\left[B_{w}\left(H_{b}+H_{a}\right)+D_{f} B_{f}\right] \\
& +\frac{C_{s}}{C_{c}}\left[\pi \mathrm{Di}\left(A_{w h}+A_{w v}+A_{f t}+A_{f l}\right) \rho_{s}\right] \\
& +\frac{C_{f}}{C_{c}}\left[2 \pi D i\left(H_{b}+H_{a}+D_{f}\right)\right]
\end{aligned}
$$

If cost of excavation is taken into account the TCR function can be formulated as

$$
\begin{aligned}
\frac{C_{T}}{C_{c}}= & \pi \operatorname{Di}\left[B_{w}\left(H_{b}+H_{a}\right)+D_{f} B_{f}\right] \\
& +\frac{C_{s}}{C_{c}}\left[\pi \operatorname{Di}\left(A_{w h}+A_{w v}+A_{f t}+A_{f l}\right) \rho_{s}\right] \\
& +\frac{C_{E}}{C_{c}}\left[\pi \text { Di }\left(H_{b}+D_{f}\right) B_{f}\right]
\end{aligned}
$$

$\mathrm{C}_{\mathrm{S}} / \mathrm{C}_{\mathrm{C}}, \mathrm{C}_{\mathrm{f}} / \mathrm{C}_{\mathrm{C}}, \mathrm{C}_{\mathrm{E}} / \mathrm{C}_{\mathrm{C}}$ represents the Reinforcement Cost ratio (RCR), Formwork Cost Ratio (FCR) and Excavation Cost Ratio (ECR) respectively

\section{Load \\ 1) Dead Loads from Tank}

The Load of Shell is transferred on Ring wall while the bottom plate is distributed between ring wall and soil infill based on ratio of the bearing areas.

\section{2) Live Load from tank}

The live load from the content in the tank is transferred to ring wall and soil infill based on ratio of bearing areas. The critical among the two cases is considered for design a) when tank is filled with hydrocarbon liquid b) when tank is filled with water during hydro test.

\section{3) Wind Load on Tank}

Wind Load on the tank is calculated as per IS 875 [9]

Design Speed $\mathrm{V}_{\mathrm{z}}=\left(\mathrm{V}_{\mathrm{b}} \mathrm{k}_{1} \mathrm{k}_{2} \mathrm{k}_{3} \mathrm{k}_{4}\right)$

Where $k_{1}, k_{2}, k_{3}, k_{4}$ are the coefficients to take account of risk, height and terrain, local topography and cyclonic possibilities respectively.

Wind pressure at height is calculated as $\mathrm{p}_{\mathrm{z}}=0.6 \mathrm{~V}_{\mathrm{z}}^{2}$

Design wind pressure, $\mathrm{p}_{\mathrm{d}}=\left(\mathrm{K}_{\mathrm{d}} \mathrm{K}_{\mathrm{a}} \mathrm{K}_{\mathrm{c}}\right) \mathrm{p}_{\mathrm{z}}$

Where $K_{d}, K_{a}, K_{c}$ are the coefficients to take account of wind directionality, area and combination effect respectively. 
Finally, the Design wind force $F_{w}=C_{f} A_{t} p_{d}$

$\mathrm{C}_{\mathrm{f}}, \mathrm{A}_{\mathrm{t}}$ are the Force coefficient and Frontal Area respectively

The Moment at bottom of tank transferred to ring wall can be calculated as

$\mathrm{M}_{\mathrm{w}}=\mathrm{F}_{\mathrm{w}}$ (height of CG of tank)

\section{4) Seismic Load}

Seismic Load on the tank is calculated as per IS 1893 [10] Design Seismic Force Fs=Z/2 I/R Sa/g

Where $\mathrm{Z}$ is the zone factor as per the different earthquake zones, I is the Importance factor, $\mathrm{R}$ is the Response reduction Factor and $\mathrm{Sa} / \mathrm{g}$ is the spectral acceleration coefficient

The Moment at bottom of tank coming on ring wall can be calculated as

$\mathrm{M}_{\mathrm{s}}=\mathrm{F}_{\mathrm{s}}$ (height of CG of tank)

\section{5) Load Combinations}

The Load Combinations for the above load cases have been considered as per IS 456.

\section{Design Constraints}

1) For Footing

$\mathrm{p}_{\max } \leq \mathrm{SBC}$ (allowable)

(The maximum bearing pressure shall be less than allowable bearing capacity of soil.)

$p_{\min } \geq 0$

(The minimum bearing pressure shall be greater than zero so that there is no loss of contact)

$\mathrm{M}_{\mathrm{d}} \leq \mathrm{kf}_{\mathrm{ck}} \mathrm{bd}^{2}(\mathrm{k}=0.138$ for Fe415, 0.133 for Fe500)

(The design moment shall be less than resisting moment capacity of the cross section)

$\mathrm{pt} \geq \mathrm{pt}_{\text {reqd }}$

where $\mathrm{pt}_{\text {reqd }}=0.5 * \mathrm{f}_{\mathrm{ck}} / \mathrm{f}_{\mathrm{y}} *\left(1-\operatorname{sqrt}\left(1-4.6 \mathrm{M}_{\mathrm{d}} /\left(\mathrm{f}_{\mathrm{ck}} \mathrm{bd} \mathrm{d}^{2}\right)\right)\right.$

(The reinforcement provided should satisfy internal force equilibrium)

$\mathrm{pt} \geq \mathrm{pt}_{\mathrm{min}}$

(The reinforcement provided shall be more than the minimum reinforcement requirement as per IS 456)

$$
\tau_{\mathrm{v}} \leq \tau_{\mathrm{c}}
$$

(The design one way shear stress shall be less than the shear capacity of the section)

2) For Ring Wall

$$
\mathrm{B}_{\mathrm{w}}>\mathrm{B}_{\min }
$$

(The width of ring wall should satisfy minimum width based on clearance requirements around anchor bolts, placement of tank)

$$
\mathrm{T} \leq 0.87 \text { fy } \mathrm{A}_{\mathrm{wh}}
$$

(The tensile load on wall because of the hoop stress shall be less than tensile capacity of reinforcement)

$\mathrm{pt} \geq \mathrm{pt}_{\min }$

(The reinforcement provided shall be more than the minimum reinforcement requirement as per IS 456)

3) Combined Footing and Ring Wall

Stabilizing Moment/Overturning Moment $\geq 1.5$

Retrieval Number: C6572029320/2020@BEIESP
Stabilizing Force/Sliding Force $\geq 1.5$

\section{4) Industry Practices}

As per PIP STE03020 [11] the difference in settlement between ring wall and soil infill shall be within $5 \%$.

\section{Optimization based on minimum cost design}

The optimum cost design of reinforced concrete ring wall under the limit state method can be stated as follows:

For given material properties, loading data and constant parameters, determine the design variables defined in Table 1a in order to minimize the total cost function defined in Eq. (1) to (4) subjected to the loads under C (1) to C (5) and design constraints given in Eq. (5) through Eq. (16).

\section{E. Solution methodology: Genetic Algorithm method}

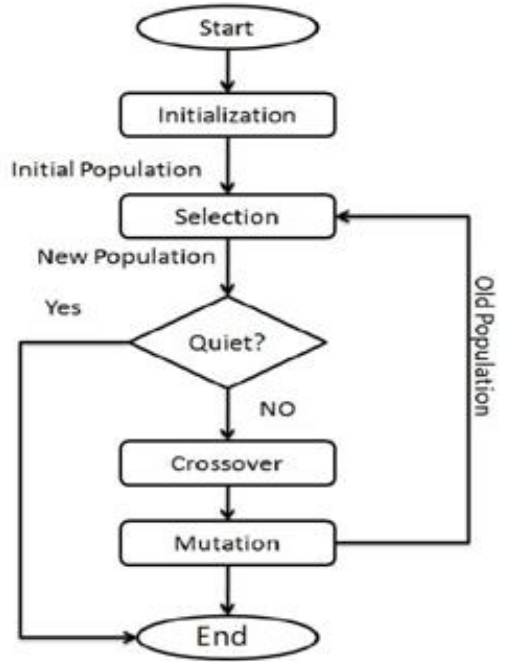

Fig. 6.Flowchart of Genetic Algorithm[14]

As Genetic algorithms abstract the problem space as a population of individuals, and try to explore the fittest individual by producing generations iteratively evolving a population of high quality individuals, where each individual represents a solution of the problem to be solved. The quality of each rule is measured by a fitness function as the quantitative representation of each rule's adaptation to a certain environment. The procedure starts from an initial population of randomly generated individuals. During each generation, three basic genetic operators are sequentially applied to each individual with certain probabilities, i.e. selection, crossover and mutation. The GAs is computer program that simulate the heredity and evolution of living organisms. An optimum solution is possible even for multi modal objective functions utilizing GAs because they are multi-point search methods. Also, GAs is applicable to discrete search space problems. Thus, GA is not only very easy to use but also a very powerful optimization tool. In GA, the search space consists of strings, each of which representing a candidate solution to the problem and are termed as chromosomes. The objective function value of each chromosome is called its fitness value. Population is a set of chromosomes along with their associated fitness.

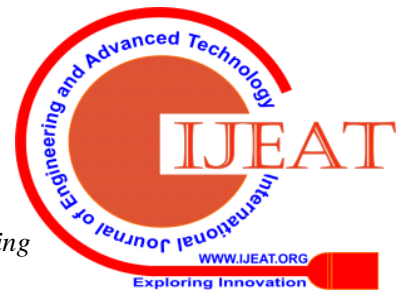


Generations are populations generated in an iteration of the GA.[13] The programming was done in MATLAB [15].

Three files were created two for calculating constraint and fitness functions and third as a control interface between the two.The control interface first initiates the iteration by assuming some random values for the population or group of variables defined in Table I. These iterative values then go into the constraint function where the constraints (5) to (16) are programmed. The code allows only those iterations which satisfies the constraints to go through to the fitness function programmed in accordance to Equation (2) to (4). Finally the fitness values or cost ratio is recorded and compared with values from other iterations consisting of a different population group. Based on the ranking of the population groups in accordance to the fitness values, cross over and mutation is performed among the high ranked groups to

narrow down to the fittest individual values of variables giving the optimal cost ratio.

\section{NUMERCIAL EXAMPLE AND STUDY SCOPE DESCRIPTION}

\section{A. Design example I}

The design example of footing optimization considered is as follows

Height of Tank=10 m, Diameter of Tank $=8 \mathrm{~m}$ to $24 \mathrm{~m}$, Grade of Concrete M30, Grade of Steel Fe500, Basic Wind Speed $=47 \mathrm{~m} / \mathrm{s}$, Seismic Zone III, SBC considered is $15 \mathrm{~T} / \mathrm{m}^{2}$ at $2 \mathrm{~m}$ below ground level and $\mathbf{R C R}=0.01$.

We have considered thickness of $300 \mathrm{~mm}$ as the lower limit of wall and footing thicknesses as per industry design practices. Also minimum percentage of reinforcement is limited to $0.12 \%$ as per IS456.

Table- IV: Results from the MATLAB program for Design Example 1

\begin{tabular}{|l|l|l|l|l|l|}
\hline $\begin{array}{l}\mathrm{Di} \\
(\mathrm{mm})\end{array}$ & $\begin{array}{l}\mathrm{B}_{\mathrm{rw}} \\
(\mathrm{mm})\end{array}$ & $\begin{array}{l}\mathrm{D}_{\mathrm{f}} \\
(\mathrm{mm})\end{array}$ & $\begin{array}{l}\mathrm{B}_{\mathrm{f}} \\
(\mathrm{mm})\end{array}$ & $\begin{array}{l}\mathrm{pt} \\
(\%)\end{array}$ & $\begin{array}{l}\mathrm{A}_{\mathrm{wh}} \\
\mathrm{mm}^{2}\end{array}$ \\
\hline 8000 & 300 & 301 & 450 & 0.12 & 2683 \\
\hline 10000 & 300 & 300 & 445 & 0.12 & 3335 \\
\hline 12000 & 329 & 309 & 460 & 0.12 & 3966 \\
\hline 14000 & 445 & 306 & 775 & 0.12 & 4733 \\
\hline 16000 & 495 & 302 & 533 & 0.12 & 5272 \\
\hline 18000 & 435 & 364 & 896 & 0.12 & 5918 \\
\hline 20000 & 325 & 510 & 1235 & 0.12 & 6230 \\
\hline 22000 & 332 & 326 & 1455 & 0.12 & 7628 \\
\hline 24000 & 586 & 418 & 1190 & 0.12 & 7704 \\
\hline 26000 & 517 & 301 & 1536 & 0.12 & 9031 \\
\hline 28000 & 684 & 341 & 1480 & 0.17 & 9444 \\
\hline 30000 & 651 & 366 & 1828 & 0.13 & 10126 \\
\hline
\end{tabular}

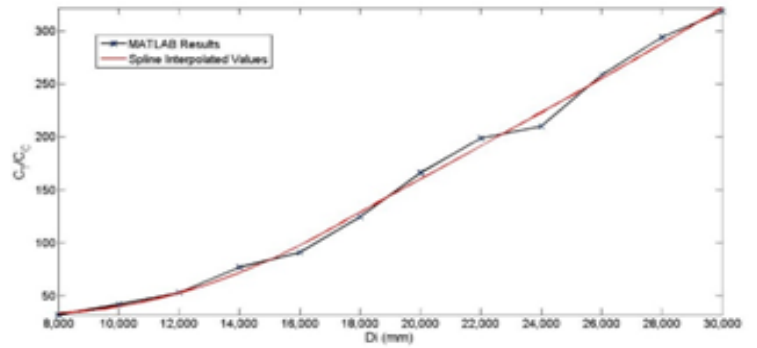

Fig. 7.Variation of TCR for different diameters of Tank The results from the MATLAB Genetic Algorithm program are shown in Table 2 .The optimal TCR obtained for the parameters in table 2 from the Equation (2) are plotted wrt the tank internal diameter which can be seen in Fig 3. It can also be seen from the figure that TCR increases non-linearly with the increase in internal diameter of Tank. The values calculated by the program are cross checked with standard excel sheets to verify whether they represent the minimum TCR values. It has been found that the results of the program converges with the minimum values. For clarity in analysis of the results, the spline interpolated curve is also shown. The spline interpolated values are within $5 \%$ of program calculated values for all the cases and hence have been considered as basis for our comparative study which follows. (Please note pt in Table 2 represents percentage of main reinforcement provided in the footing and is directly proportional to main reinforcement in footing)

\section{B. Parametric study and Sensitivity Analysis}

In this paper the parametric study has been carried out for small (upto $18 \mathrm{~m}$ in diameter) and medium (18 to $30 \mathrm{~m}$ diameter) tanks. The analysis has been carried out in 3 parts. In the first part the effect of variation of the different design characteristic on the TCR value have been analysed. In the second part the effect the effect of varying the loads on the TCR value have been analysed. Finally in the third part the effect of Formwork and Excavation costs on the TCR value have been analysed. The minimum cost value have been considered as basis of comparison during the parametric study. In the first and second study the effect formwork and earthwork excavation are not considered. The effect of their costs are taken up in the third study for clarity on their roles. Due to these variation as mentioned above there will also be variation in the variables shown in Table 1 as per design which will then influence the total cost.

1) Effect of Design Characteristic of Material on the $C_{T} / C_{C}$ value

Table- V: Constant and Variable parameters of the Parametric Study 1).

\begin{tabular}{l|l|l|}
\hline $\begin{array}{l}\text { Case } \\
\text { Study }\end{array}$ & $\begin{array}{l}\text { Constant Parameters and } \\
\text { Values }\end{array}$ & Variables and range \\
\hline I & $\begin{array}{l}\mathrm{H}_{\mathrm{t}}=10 \mathrm{~m}, \\
\mathrm{H}_{\mathrm{b}}=2 \mathrm{~m} \\
\mathrm{SBC}=15 \mathrm{~T} / \mathrm{m}^{2}, \quad \text { RCR } \\
\mathrm{f}_{\mathrm{y}}=\mathrm{Fe} 500, \quad \mathrm{Di}=8 \mathrm{~m} \text { to } 30 \mathrm{~m}, \\
=0.01\end{array}$ & $\mathrm{f}_{\mathrm{ck}}=\mathrm{M} 25, \mathrm{M} 35, \mathrm{M} 45$ \\
&
\end{tabular}
Published By:
Blue Eyes Intelligence Engineering
\& Sciences Publication




\begin{tabular}{|c|c|c|c|}
\hline II & $\begin{array}{l}\mathrm{H}_{\mathrm{t}}=10 \mathrm{~m}, \\
\mathrm{H}_{\mathrm{b}}=2 \mathrm{~m}, \\
\mathrm{SBC}=15 / \mathrm{m}^{2}, \\
\mathrm{f}_{\mathrm{ck}}=\mathrm{M} 30 \\
=0.01\end{array}$ & RCR & $\begin{array}{l}\mathrm{Di}=8 \mathrm{~m} \text { to } 30 \mathrm{~m}, \mathrm{f}_{\mathrm{y}}= \\
\mathrm{Fe} 415, \mathrm{Fe} 500\end{array}$ \\
\hline
\end{tabular}

2) Effect of Loading on the $C_{T} / C_{C}$ value

Table- VI: Constant and Variable parameters of the Parametric Study 2).

\begin{tabular}{|c|c|c|}
\hline $\begin{array}{l}\text { Case } \\
\text { Study }\end{array}$ & $\begin{array}{l}\text { Constant Parameters } \\
\text { and Values }\end{array}$ & Variables and range \\
\hline III & $\begin{array}{l}\mathrm{H}_{\mathrm{t}}=10 \mathrm{~m} \\
\mathrm{H}_{\mathrm{b}}=2 \mathrm{~m} \\
\mathrm{SBC}=15 \mathrm{~T} / \mathrm{m} 2 \\
\mathrm{f}_{\mathrm{ck}}=\mathrm{M} 30 \\
\mathrm{f}_{\mathrm{y}}=\mathrm{Fe} 500 \\
\mathrm{RCR}=0.01\end{array}$ & $\begin{array}{l}\mathrm{Di}=8 \mathrm{~m} \text { to } 30 \mathrm{~m} \text {, } \\
\text { Wind loading } \\
\text { parameters varied } \\
\text { according to wind } \\
\text { zones } 33 \mathrm{~m} / \mathrm{s} \text { to } 55 \\
\mathrm{~m} / \mathrm{s}\end{array}$ \\
\hline IV & $\begin{array}{l}\mathrm{H}_{\mathrm{t}}=10 \mathrm{~m}, \\
\mathrm{H}_{\mathrm{b}}=2 \mathrm{~m}, \\
\mathrm{SBC}=15 \mathrm{~T} / \mathrm{m} 2, \\
\mathrm{f}_{\mathrm{ck}}=\mathrm{M} 30, \\
\mathrm{f}_{\mathrm{y}}=\mathrm{Fe} 500, \\
\mathrm{RCR}=0.01\end{array}$ & $\begin{array}{l}\mathrm{Di}=8 \mathrm{~m} \text { to } 30 \mathrm{~m} \text {, } \\
\text { Seismic loading } \\
\text { parameters varied } \\
\text { according to seismic } \\
\text { zones II, III, IV }\end{array}$ \\
\hline V & $\begin{array}{l}\mathrm{H}_{\mathrm{b}}=2 \mathrm{~m}, \\
\mathrm{SBC}=15 \mathrm{~T} / \mathrm{m} 2, \\
\mathrm{f}_{\mathrm{ck}}=\mathrm{M} 30, \\
\mathrm{f}_{\mathrm{y}}=\mathrm{Fe} 500, \\
\mathrm{RCR}=0.01\end{array}$ & $\begin{array}{l}\mathrm{Di}=8 \mathrm{~m} \text { to } 30 \mathrm{~m}, \mathrm{H}_{\mathrm{t}}= \\
10 \mathrm{~m} \text { to } 24 \mathrm{~m}\end{array}$ \\
\hline
\end{tabular}

3) Effect of cost of materials on the CT/CC value

Table- VII: Constant and Variable parameters of the Parametric Study 3).

\begin{tabular}{|l|l|l|}
\hline $\begin{array}{l}\text { Case } \\
\text { Study }\end{array}$ & $\begin{array}{l}\text { Constant Parameters } \\
\text { and Values }\end{array}$ & Variables and range \\
\hline VI & $\mathrm{H}_{\mathrm{t}}=10 \mathrm{~m}$, & Two cases one \\
& $\mathrm{H}_{\mathrm{b}}=2 \mathrm{~m}$, & considering \\
& $\mathrm{SBC}=15 \mathrm{~T} / \mathrm{m}^{2}$, & formwork cost and \\
& $\mathrm{f}_{\mathrm{ck}}=\mathrm{M} 30$, & other without it. \\
& $\mathrm{f}_{\mathrm{y}}=\mathrm{Fe} 500$, & \\
& $\mathbf{R C R}=0.01$ & Two cases one \\
\hline VII & $\mathrm{H}_{\mathrm{t}}=10 \mathrm{~m}$, & considering \\
& $\mathrm{H}_{\mathrm{b}}=2 \mathrm{~m}$, & earthwork excavation \\
& $\mathrm{SBC}=15 \mathrm{~T} / \mathrm{m}^{2}$, & cost and other without \\
& $\mathrm{f}_{\mathrm{ck}}=\mathrm{M} 30$, & it. \\
& $\mathrm{f}_{\mathrm{y}}=\mathrm{Fe} 500$, & \\
\hline & $\mathbf{R C R}=0.01$ & \\
\hline
\end{tabular}

\section{RESULTS AND DISCUSSION OF STUDY}

\section{A. Case Study I}

When the grade of concrete increases keeping other parameters constant as in Table V, it is observed from Fig 8 that the value of TCR doesn't have any significant variation till $18 \mathrm{~m}$ internal tank diameter it means grade of concrete is insensitive for smaller diameter tanks. After 18m diameter onwards difference in TCR gradually increases from higher grade of concrete to lower grade of concrete. For medium tank diameters, there is cost saving of up to $10 \%$ for higher grade over lower grade of concrete.

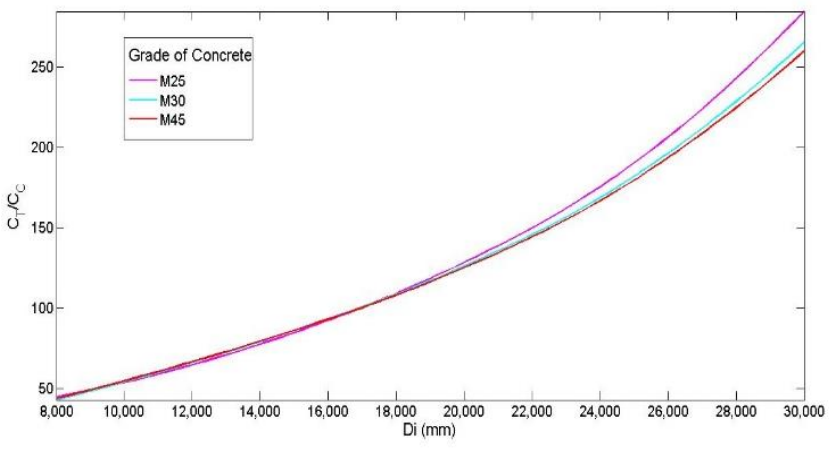

Fig. 8.TCR vs Internal Diameter of tank for different grade of concrete

\section{B. Case Study II}

When the grade of reinforcement increases keeping other parameters constant as in Table V, it is observed from Fig 9 that the value of TCR doesn't have any significant variation for small diameter tanks. A small variation is observed beyond $26 \mathrm{~m}$. After $26 \mathrm{~m}$ diameter onwards the value of TCR slightly decreases as the reinforcement grade increases. Therefore, grade of reinforcement is insensitive to total cost of foundation for small and medium diameter tanks.

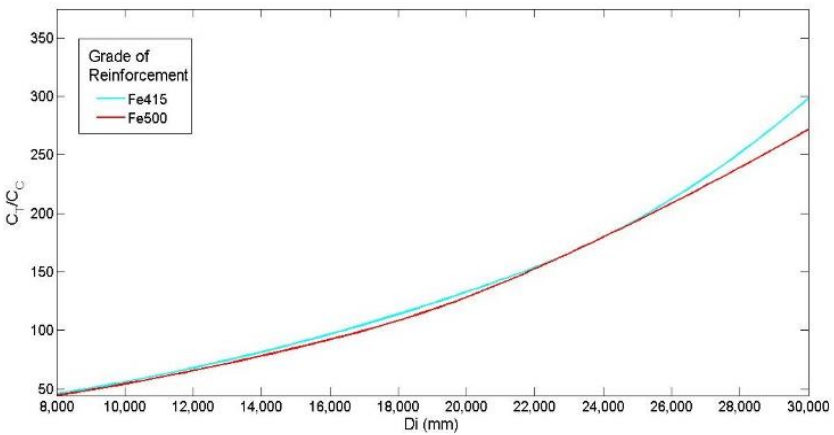

Fig. 9.TCR vs Internal Diameter of tank for different grade of Reinforcement

\section{Case Study III}

When the basic wind speed increases according to wind zones keeping other parameters constant as in Table VI, it is observed from Fig 10 that the value of TCR increases as the wind speed increases. From small diameter tanks (upto 18m) and medium tanks (18m to $30 \mathrm{~m}$ ) TCR increases by $33 \%$ when wind speed increases by $50 \%$ from $33 \mathrm{~m} / \mathrm{s}$ to $50 \mathrm{~m} / \mathrm{s}$. However for very high windspeeds of $55 \mathrm{~m} / \mathrm{s}$ sharper increase in TCR is observed as tank diameter become larger.

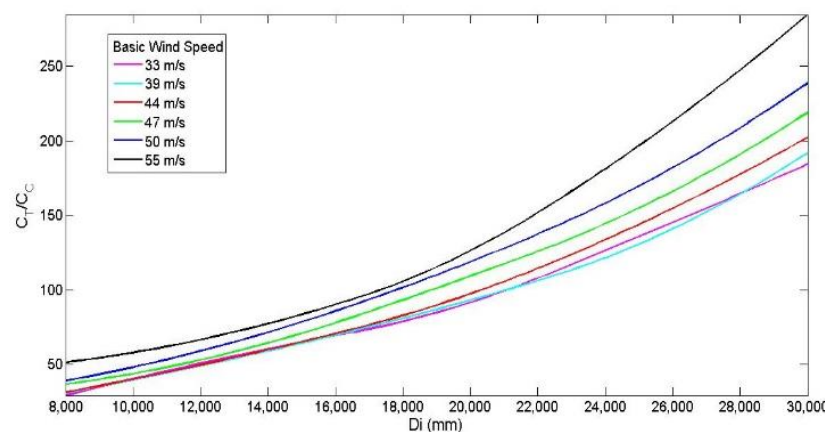

Fig. 10. Total Cost Ratio vs Internal Diameter of tank for different wind speed zones

Published By: 


\section{Case Study IV}

When the earthquake load increases according to earthquake zones keeping other parameters constant as in Table VI, it is observed from Fig 11 that the value of TCR increases. It can be seen that as the diameters of tank increases the TCR for different earthquake zones increases. For small tanks (upto $18 \mathrm{~m}$ in diameter), the variation in TCR is up to $50 \%$ for each increase in Zone (between Zone II Zone III / Zone III-Zone IV). Similar trends are also observed for medium tanks (from $18 \mathrm{~m}$ to $30 \mathrm{~m}$ in diameter). Zone $\mathrm{V}$ hasnot been considered in our study as the type of footing changes from annular to full raft

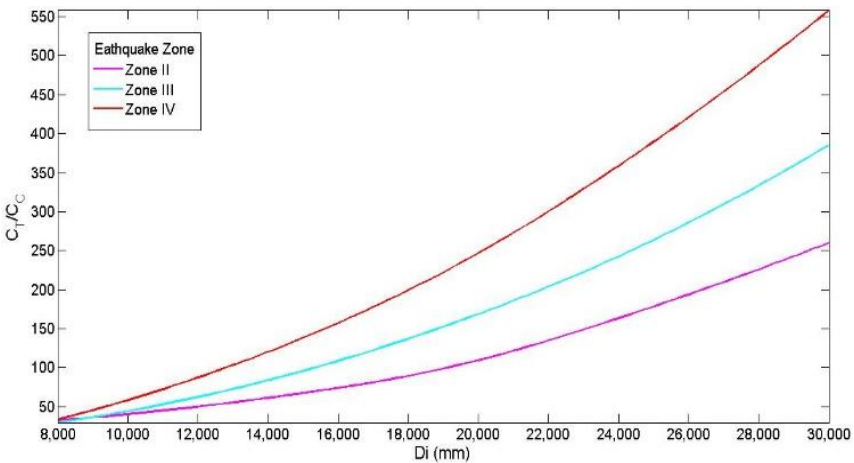

Fig. 11. TCR vs Internal Diameter of tank for different seismic zones

\section{E. Case Study V}

When the height increases keeping other parameters constant as in Table VI, it is observed from Fig 12 that the value of TCR increases. It can also be seen that as the diameters of tank increases the difference between TCR for different height increases. Increase in TCR for small and medium tanks when height is doubled the increase in TCR is around to $35-40 \%$.

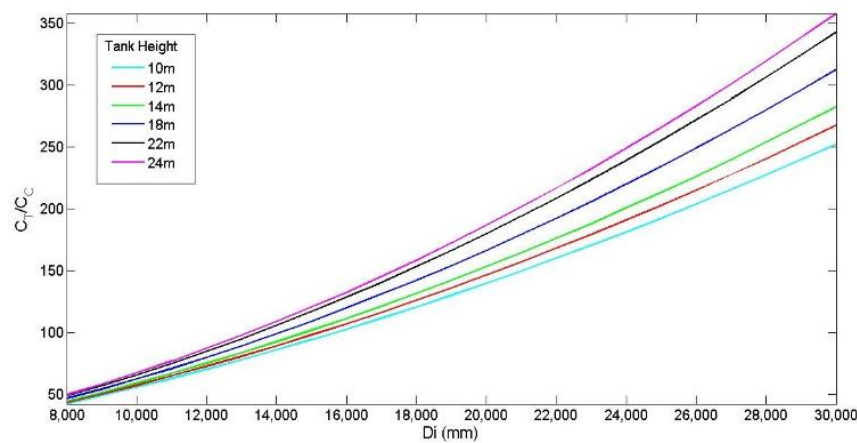

Fig. 12. TCR vs Internal Diameter of tank for different height of tank

\section{F. Case Study VI}

When formwork cost is included keeping other parameters constant as in Table VII, it is observed from Fig 13 that the value of TCR increases at a constant proportion. Hence we can concluded that for both small and medium diameter tanks the effect of shuttering is constant across all diameters.

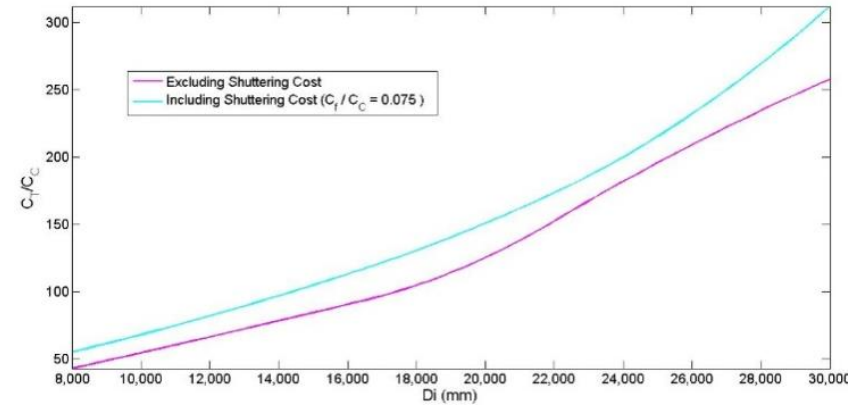

Fig. 13. TCR vs Internal Diameter of tank showing the effect of including formwork cost

\section{G. Case Study VII}

When excavation cost is included keeping other parameters constant as in Table VII, it is observed from Fig 14 that the value of TCR increases constantly for both small and medium diameter tanks. However the increase for medium diameter tanks is almost twice that of small diameter tanks.

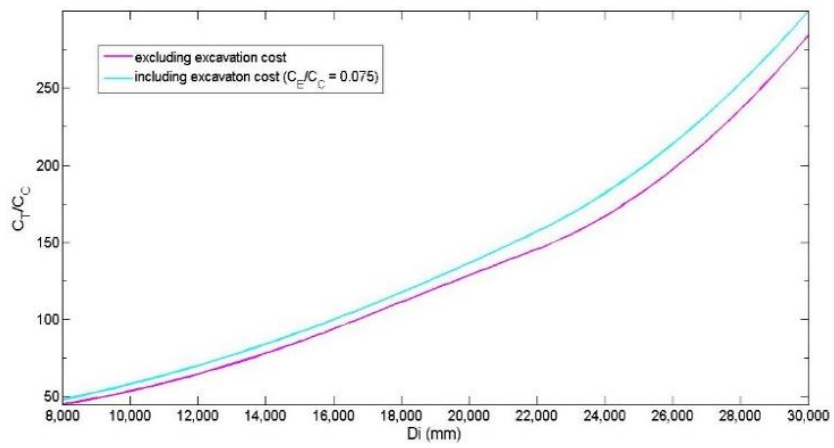

Fig. 14. TCR vs Internal Diameter of tank showing the effect of including excavation cost

\section{CONCLUSION}

This paper attempts to assess the application of using genetic algorithm to develop sensitivity analyzing of optimal cost of RC ring wall foundation for the following parameters: -grade of steel -grade of concrete -variation in wind speed -seismic zones -height and diameter of tanks

The key findings from the study can be summarized as follows:Grade of concrete is insensitive for small diameter tanks, savings in the range of $6 \%$ to $10 \%$ by using higher grade of concrete may be achieved for medium diameter

1) Grade of reinforcement is insensitive for both small diameter and medium diameter tanks.

2) Increase of wind speed by 50\%, increases cost of foundations for small and medium diameter tanks by 33\%.

3) Earth quake zone has significant impact on the cost of tank foundation. Cost of tank foundation increases by $50 \%$ for both small and medium tanks across each increase in seismic zone.

4) The optimal solution is found to be insensitive to shear.

5) When the height of tank increases by $100 \%$, the cost of foundation increases upto $35 \%-40 \%$ across all diameters.

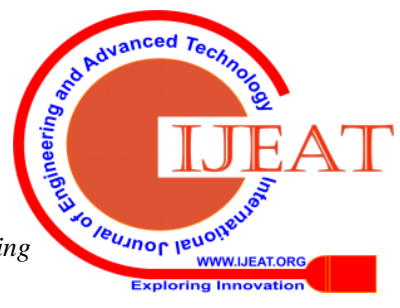


6) The effect of formwork cost on the overall cost of ringwall foundation is constant for both small and medium diameter tanks.

7) The effect of earthwork excavation cost plays a minor role in the overall cost of the tank for small diameter tanks whereas for medium diameter tanks the impact is twice than that of small diameter tanks.

The future scope for extending this study includes considering for large diameter of tanks where there is significant increase in loading and require special type of foundation arrangement.

There is also further scope to include the impact of soil parameters like bearing capacity, depth of foundation on the optimal cost of RC ring walls and for pile foundations.

The methodology for optimizing cost using genetic algorithm is effective and its application for parametric studies appears feasible for diverse design factors applicable to RC ring wall design Sensitivity of the design factors on cost of the RC ring wall foundation can be easily developed . In large projects this vital information can help in taking timely decisions for finalizing engineering design, material procurement etc. can contribute to substantial cost savings as well timely execution minimizing project delays. The results from the parametric study and sensitivity analysis could be used in predictive modelling for costing and budgeting in the engineering and construction industry related to Oil, Gas and Hydrocarbon.

\section{REFERENCES}

1. Malleshappa Malapur M, Prateek Cholappanavar, R. J. Fernandes, Optimization of RC Column and Footing using Genetic Algorithm, International Research Journal of Engineering and Technology (IRJET), Vol. 05, August 2018 pp 546-552.

2. Sasidhar T, Neeraja D, V Samba Murthy Sudhindra, Application of Genetic Algorithm technique for optimizing design of RC Retaining Wall, International Journal of civil engineering and Technology Vol 08 , May 2017, pp 999 -1007.

3. Rajeev S and Krishnamoorthy C S, Genetic Algorithm-Based Methodology for Design Optimization of Reinforced Concrete Frames, Computer-Aided Civil and Infrastructure Engineering, Vol-13, January 1998,pp 63-74,.

4. Renitha TV, Raghunandan Kumar, Optimized cost design of RC Frame, International Journal of Engineering and Advanced Technology, Vol 05, April 2016, pp. 194-199.

5. Fedghouche Ferhat, Design Optimization of Reinforced Ordinary and High-Strength Concrete Beams with Eurocode2 (EC-2), Optimum Composite structures, IntechOpen, 2019, Chapter 7.

6. Aga A, Adam F M, Design Optimization of Reinforced Concrete Frames, Open Journal of Civil Engineering, Vol 5, March 2015, pp 74-83.

7. S. N. Sivanandam, S. N. Deepa, Introduction of Genetic Algorithm, Springer, 2008

8. IS 456, "Plain and Reinforced Concrete-Code of Practice", 2000

9. IS 875 (part 3), Design Loads (Other than Earthquake) for Building and Structures - Code of practice, 2015.

10. IS 1893 (part 1), Criteria for Earthquake Resistant Design of structures, 2016.

11. Process Industry practices, STE03020, Guidelines for Tank foundation designs, 2015.

12. J H Holland, Adaptation in Natural and Artificial Systems. AnnArbor, MI: MIT Press, 1975.

13. L. Haldurai, T. Madhubala and R. Rajalakshmi, A Study on Genetic Algorithm and its Applications, International Journal of Computer Sciences and Engineering, Vol 04, October 2016, pp 139-143.

14. Amin Dastanpour and Raja Azlina Raja Mahmood, Feature Selection Based on Genetic Algorithm and Support Vector Machine for Intrusion Detection System, The Second International Conference on Informatics Engineering \& Information Science (ICIEIS2013), November 2013, pp 169-181

15. Mathworks Inc., Genetic algorithm solver for mixed-integer or continuous-variable optimization, constrained or unconstrained: User's Guide (R2019b)

https://in.mathworks.com/help/gads/genetic-algorithm.html

\section{AUTHORS PROFILE}

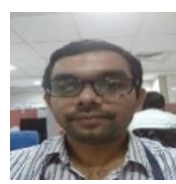

Gautam Acharyya is a BTech in Civil engineering from IIT Kharagpur. He has 10 years of Industry experience as a Civil and Structural Design Engineer. He is currently working as Deputy Manager in the Civil Engineering Department of Oil, Gas and Hydrocarbon division, Tata Projects Limited, Mumbai. He has also previously worked in ANSYS Inc.

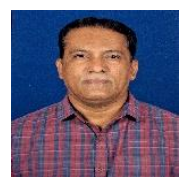

Sridhar Reddy E is a ME in Structural Engineering with more than 25 years of industry experience and is a Fellow of Institution of Engineers and a Chartered Engineer. He is currently General Manager in Oil, Gas and Hydrocarbon division of Tata Projects Limited, Mumbai.

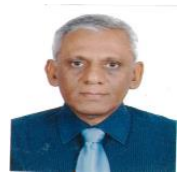

Pralhad Pawar is a BTech from IIT Bombay and Masters in Financial Management from Jamnalal Bajaj Institute of Management Studies. He has more than 35 years of Industry Experience. He is currently working as the Chief Technology \& Engineering Officer in Tata Projects Limited, Mumbai. 